\title{
Freestanding $\mathrm{MoO}_{3-\mathrm{x}}$ nanobelt/carbon nanotube films for Li-ion intercalation pseudocapacitors
}

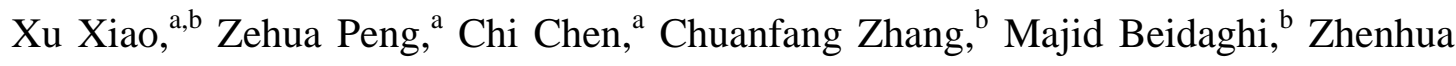
Yang, ${ }^{\mathrm{c}}$ Nan Wu, ${ }^{\mathrm{a}}$ Yunhui Huang, ${ }^{\mathrm{d}}$ Ling Miao, ${ }^{\mathrm{a}}$ Yury Gogotsi, ${ }^{\mathrm{b}}$ and Jun Zhou ${ }^{\mathrm{a} *}$

${ }^{a}$ Wuhan National Laboratory for Optoelectronics, School of Optical and Electronic Information, Huazhong University of Science and Technology, Wuhan 430074, P. R. China

${ }^{\mathrm{b}}$ Department of Materials Science and Engineering, A.J. Drexel Nanotechnology Institute, Drexel University, Philadelphia, PA 19104, USA

${ }^{c}$ Faculty of Materials, Optoelectronics and Physics, Key Laboratory of Low

Dimensional Materials \& Application Technology of Ministry of Education, Xiangtan University, Xiangtan 411105, Hunan, China

${ }^{\mathrm{d}}$ School of Materials Science and Engineering

Huazhong University of Science and Technology, Wuhan 430074, Hubei, P. R. China * Corresponding author.

E-mail address: jun.zhou@ mail.hust.edu.cn

Abstract Molybdenum trioxide $\left(\mathrm{MoO}_{3}\right)$ is known as a promising pseudocapacitive material, but low conductivity limits its applications. Hydrogenation is demonstrated to increase the conductivity of $\mathrm{MoO}_{3}$ and hence improve its electrochemical performance. Hydrogenated $\mathrm{MoO}_{3}\left(\mathrm{MoO}_{3-\mathrm{x}}\right)$ shows enhanced conductivity based on both of first principle calculation and single nanobelt measurement. Freestanding $\mathrm{MoO}_{3-\mathrm{x}} /$ carbon nanotubes (CNT) composite films have been fabricated and showed much improved electrochemical performance compared to composites of CNT and as-synthesized $\mathrm{MoO}_{3}\left(\mathrm{MoO}_{3} / \mathrm{CNT}\right)$. Electrodes showed a specific capacitance of 337 $\mathrm{F} / \mathrm{g}$ (based on the mass of $\mathrm{MoO}_{3-\mathrm{x}}$ ) and a high volumetric capacitance of $291 \mathrm{~F} / \mathrm{cm}^{3}$ (based on the whole electrode) with excellent rate capability. Also we confirmed the improved intercalation kinetics and the increased intercalation pseudocapacitance 
could be attributed to the higher electronic conductivity of $\mathrm{MoO}_{3-\mathrm{x}}$, which results in better and faster intercalations of $\mathrm{Li}^{+}$ions. This electrochemical behavior implies that $\mathrm{MoO}_{3-\mathrm{x}}$ can serve as a very good negative electrode with high capacitance at high mass loading levels.

Keywords: $\mathrm{MoO}_{3}$ nanobelts, pseudocapacitor, intercalation, freestanding, hydrogenated

\section{Introduction}

Renewable energy sources, such as solar cell, are promising to meet energy requirements of the further portable electronics,${ }^{[1-2]}$ but development of energy storage devices $^{[3-5]}$ that can be coupled with these energy sources is necessary for the effective utilization of green and renewable energy sources. ${ }^{[6-8]}$ By virtue of their fast charge/discharge rate, high power density and long cyclic life, supercapacitors (SCs) have a potential to provide efficient energy storage for intermittent energy sources. ${ }^{[9-12]}$ From the equations of energy $\left(E=0.5 C V^{2}\right)$ and power $\left(P=0.25 V^{2} / R\right)$ density, where $C$ is the capacitance, $R$ is the internal resistance and $V$ is the working potential window, enlarging the potential window represents a promising way to enhance both energy and power densities of supercapacitors. ${ }^{[13-14]}$ Recently, many groups have reported the fabrication of asymmetrical SCs by combining different positive and negative electrodes to achieve a larger working potential window and thus higher energy and power densities. Examples of these kind of devices are graphene/ $\mathrm{MnO}_{2} / /$ activated carbon and graphene/ $\mathrm{MnO}_{2} / /$ graphene systems. ${ }^{[15-17]}$ The reported negative electrodes are largely confined to carbonaceous materials due to their good conductivity. Such a carbon-based asymmetrical SC typically shows excellent power performance, but the energy density of the cell is greatly limited by a lower capacitance of the negative electrode. Although some other materials, such as $\mathrm{Fe}_{2} \mathrm{O}_{3}$ and $\mathrm{Fe}_{3} \mathrm{O}_{4}$, have also been studied, their low conductivity largely hinders their performance, especially for high mass loadings of the electrodes. ${ }^{[18]}$ It's therefore important to develop suitable negative electrode materials with both high capacitance and good rate capability 
especially under high mass loading.

Compared to the electrostatic storage of charge in electric double layer capacitors (EDLCs), pseudocapacitors can provide larger capacity and energy density through reversible redox reaction. ${ }^{[19]}$ Recently, Dunn and co-workers demonstrated a new kind of pseudocapacitance resulting from ion intercalation. ${ }^{[20]}$ In layered or tunneled materials, ions can easily intercalate into the channels between oxide layers. Molybdenum oxide $\left(\mathrm{MoO}_{3}\right)$, which has a layered structure with superior ion intercalation capability, has been widely studied in electrochemical storage, especially in lithium ion batteries. ${ }^{[21-22]}$ Although we and other groups have pointed out the feasibility of using $\mathrm{MoO}_{3}$ or $\mathrm{MoO}_{3-\mathrm{x}}$ as a negative electrode in SCs, few studies have focused on capacitive behavior of $\mathrm{MoO}_{3}$ due to its naturally poor conductivity and rate capability. ${ }^{[21,23-24]} \mathrm{MoO}_{3}$ would be a suitable negative electrode material if the key problem of poor conductivity could be solved.

Herein, hydrogenation was used to increase the conductivity of $\mathrm{MoO}_{3}$. We hypothesized that controlled introduction of oxygen vacancies could improve the conductivity of $\mathrm{MoO}_{3}$, and promote the electrochemical performance. In order to prepare electrodes with good mechanical stability and high volume/mass utilization, the hydrogenated $\mathrm{MoO}_{3}\left(\mathrm{MoO}_{3-\mathrm{x}}\right)$ was vacuum filtrated with carbon nanotubes (CNTs) to form a freestanding $\mathrm{MoO}_{3-\mathrm{x}} / \mathrm{CNT}$ film. A specific capacitance of $337 \mathrm{~F} / \mathrm{g}$ and a high volumetric capacitance of $291 \mathrm{~F} / \mathrm{cm}^{3}$ with excellent rate capability were achieved under high mass loading. In addition, ion intercalation kinetics in $\mathrm{MoO}_{3-\mathrm{x}}$ has been systematically analyzed.

\section{Experimental}

Preparation of $\mathrm{MoO}_{3-\mathrm{x}} \cdot \mathrm{MoO}_{3}$ nanobelts were synthesized via a hydrothermal process. Specifically, $2 \mathrm{~g}$ of molybdenum powder (Aladdin, 99.5\%) was dropped into $10 \mathrm{~mL}$ deionized water and stirred to achieve a uniform mixture. Then, $20 \mathrm{~mL} \mathrm{H}_{2} \mathrm{O}_{2}$ was slowly added into the obtained mixed solution. After stirring for 30 minutes, the saffron yellow precursor was then sat for 30 minutes. The resultant solution was transferred to a Teflon-lined stainless steel autoclave and heated at $180{ }^{\circ} \mathrm{C}$ for $12 \mathrm{~h}$. 
The product precipitate was filtered and rinsed with deionized water, followed by drying at $60{ }^{\circ} \mathrm{C}$ for $12 \mathrm{~h}$. Then the $\mathrm{MoO}_{3}$ was hydrogenated in $\mathrm{H}_{2} / \mathrm{Ar}\left(10\right.$ vol. \% $\left.\mathrm{H}_{2}\right)$ at different temperatures for $5 \mathrm{~h}$ to obtain $\mathrm{MoO}_{3-\mathrm{x}}$.

Preparation of freestanding films. We used the vacuum filtration method to fabricate the freestanding films. $0.4 \mathrm{~g}$ SDS used as surfactant was dissolved in deionized water $(50 \mathrm{~mL})$ containing CNTs $\left(0.021 \mathrm{~g}\right.$, Blue Nano, China) and $\mathrm{MoO}_{3}$ $(0.039 \mathrm{~g})$, then sonicated for $20 \mathrm{~min}$. The as-obtained solution was filtered through a membrane with the $220 \mathrm{~nm}$ pore size. The obtained filter cake was dried in vacuum for $0.5 \mathrm{~h}$ and then peeled off to obtain a freestanding film.

Characterization. The morphology and structure of the samples were studied by field-emission scanning electron microscopy (FE-SEM, FEI Nova 450 Nano), high-resolution transmission electron microscopy (HRTEM, TECNAI), X-ray diffraction (XRD, X'Pert Pro, PANanalytical) and X-ray photoelectron spectroscopy (XPS, ESCALab250). First-principles calculations are performed by using SIESTA package based on density-functional theory (DFT). ${ }^{[25 a-d]}$ The exchange-correlation energy is described by the functional of Perdew-Burke-Ernzerhof (PBE) based on general gradient approximation (GGA). ${ }^{[25 e]}$ The double-zeta basis set with polarization functions and a cutoff of 150 Ryd are used. The structure optimization was carried out by relaxing the forces on all the atoms until a $0.05 \mathrm{eV} / \AA$ force tolerance is reached, using a conjugate gradient method. The energy converge is $10^{-4}$ eV. Single nanobelt device was fabricated by focused ion beam (FIB, Quanta 3D FEG) with Pt as the electrode. The test was carried out with Agilent 2400. All of the electrochemical tests were carried out using Autolab PGSTAT302N with 5M aqueous $\mathrm{LiCl}$ as the electrolyte. For the typical three-electrode configaration, $\mathrm{Ag} / \mathrm{AgCl}(\mathrm{CHI}$, USA) is the reference electrode, YP-50 (Kuraray Chemical, USA) is the counter electrode, Celgard is the separator (Celgard, USA) and all of the tests were conducted in Swagelok cells (Swagelok, USA). Electrochemical impedance was measured from $1 \mathrm{mHz}$ to $1 \mathrm{MHz}$ with a potential amplitude of $10 \mathrm{mV}$.

\section{Results and Discussion}


After hydrogenation (Figure 1a)., the color of the $\mathrm{MoO}_{3}$ powder was changed from grey-white to blue (Figure S1), demonstrating the partial reduction and introduction of oxygen vacancies in $\mathrm{MoO}_{3} .{ }^{[25 f]}$ The corresponding SEM images were shown in Figures $1 \mathrm{~b}$ and $\mathrm{c}$, indicating that the hydrogenation did not change the shape and sizes of $\mathrm{MoO}_{3}$ nanobelts, which show a lengths up to $12 \mu \mathrm{m}$. According to the transmission electron microscopy (TEM), the width of the $\mathrm{MoO}_{3-\mathrm{x}}$ nanobelts was about $200 \mathrm{~nm}$ (Figure 1d), similar to the ones published in Reference. ${ }^{[25 \mathrm{~g}]}$ HRTEM images (Figure 1e) show the interplanar spacings for the two perpendicular directions to be $\sim 0.37$ and $\sim 0.40 \mathrm{~nm}$, respectively. These values correspond to the $d_{001}$ and $d_{100}$ of the orthorhombic $\alpha-\mathrm{MoO}_{3}$ phase (JCPDS reference card no. 05-0508). ${ }^{[26-27]}$ As shown in the inset of the Figure 1e, the selected area electron diffraction (SAED) pattern also confirmed the crystal structure of $\mathrm{MoO}_{3-\mathrm{x}}$.

To further confirm the structure, X-ray diffraction (XRD) analysis was also conducted. Both patterns shown in Figure 2 a closely match that of orthorhombic $\alpha-\mathrm{MoO}_{3}$ (JCPDS reference card no. 05-0508). It should be noted that the detectable diffraction peak shift, as shown in Figure 2a, corresponds to a decreased lattice constant due to the oxygen vacancies. The relative decrease of unit cell volume was about $0.1 \%$ according to the XRD peaks shift. In addition, the detailed chemical composition was probed by XPS, as shown in Figure S3 and Figure 2b. Figure S3 show the XPS spectrum of Mo $3 \mathrm{~d}$ in $\mathrm{MoO}_{3}$, in which two strong peaks, corresponding to $\mathrm{Mo}^{6+}$, and a very weak peak corresponded to $\mathrm{Mo}^{4+}$ were found. However, two stronger peaks which correspond to $\mathrm{Mo}^{4+}$ were found in $\mathrm{MoO}_{3-\mathrm{x}}$ (the ratio of $\mathrm{Mo}^{4+} / \mathrm{Mo}^{6+}$ increased from $0.4 \%$ to $7.3 \%$ ), indicating partial reduction (Figure $2 \mathrm{~b}$ ). Based on the XPS data, the $\mathrm{x}$ could be roughly estimated to 0.07 , which may be underestimated since XPS is a surface chemical analysis technique. In order to understand the change of structure and electronic states by hydrogenation, first principle calculations (FPC) were carried out. As shown in the inset of Figure 2c, $\mathrm{MoO}_{3}$ consists of layered $\mathrm{MoO}_{6}$ octahedra. During hydrogenation, $\mathrm{H}$ prefers to react with asymmetrical $\mathrm{O}$ atoms $(\mathrm{Oa})$ on the surface of $\mathrm{MoO}_{3}$. (See details in Supporting 
Information) The band structures of perfect and defective $\mathrm{MoO}_{3}$ are shown in Figure S11. It could be seen that the Fermi energy level increases after introducing an $\mathrm{O}$ defect (Table S2). In addition, a defect level slight lower than Fermi energy level is produced within the gap. The partial density of states (PDOS) shown in Figures 2c and S12 indicate that the defect level mainly stems from the Mo 4d orbital. Hence, it could be inferred that more $4 \mathrm{~d}$ electrons coming from Mo will occupy the defect levels with the increasing number of $\mathrm{O}$ defects, resulting in the broadening of impurity band until the overlapping with conduction band. Therefore, the gap will become more narrow and the electrical conductivity of $\mathrm{MoO}_{3}$ will be elevated as a result of a large number of $\mathrm{O}$ defects. To verify this theoretical calculation, focused ion beam (FIB) lithography was applied to fabricate single-nanobelt devices of $\mathrm{MoO}_{3}$ and $\mathrm{MoO}_{3-\mathrm{x}}$ to detect the change of their conductivity. The current-voltage (I-V) curves of $\mathrm{MoO}_{3}$ and $\mathrm{MoO}_{3-\mathrm{x}}$ devices are shown in Figure 2d. The current response increases with the voltage, suggesting the increasing conductivity after hydrogenation and partial reduction, which was consistent with our hypothesis. Based on the equation:

$$
R=\rho L / S
$$

where $R$ is the resistance, $\rho$ is the resistivity, $L$ is the length of the nanobelt and $S$ is the sectional area, we calculated the resistivity of different samples. The resistivity of $\mathrm{MoO}_{3}$ was $1.6 \sim 1.8 \mathrm{E}-1 \Omega \cdot \mathrm{m}$ while $\mathrm{MoO}_{3-\mathrm{x}}$ was $2.4 \sim 4.8 \mathrm{E}-3 \Omega \cdot \mathrm{m}$ which was closed to commercial CNT $(\sim 1 \mathrm{E}-4 \Omega \cdot \mathrm{m})$. Since no change of shape and size was detected, the change of conductivity was due to the introduction of oxygen vacancies after hydrogenation. Therefore, it should be reasonably expected that $\mathrm{MoO}_{3-\mathrm{x}}$ would show enhanced electrochemical performance with good rate capability.

To confirm our hypothesis, electrochemical performance of $\mathrm{MoO}_{3-\mathrm{x}}$ was studied systematically. Here we use freestanding $\mathrm{MoO}_{3} / \mathrm{CNT}$ (65/35 wt.\%) films as electrodes to exclude the factors which would lower the conductivity so that the differences in capacitance could be directly related to the conductivity of the material itself. ${ }^{[28]}$ Besides, developing freestanding electrodes significantly simplifies electrode 
fabrication processes, maximizes the volumetric capacitance and energy/power density of the whole SC device. Figure S4 shows the optical and SEM image of the freestanding film, indicating the CNTs and $\mathrm{MoO}_{3-\mathrm{x}}$ are homogenously mixed. The electrochemical performance and electrical conductivity of the electrodes were first examined by electrochemical impedance spectroscopy (EIS). As shown in Figure S5, the diameter of the semicircle at the high frequency region was decreased from $13 \Omega$ to $1.9 \Omega$ after hydrogenation. The semicircle resistance $\left(\mathrm{R}_{\text {semi }}\right)$ includes the pseudocapacitive charge transfer resistance and contact resistance. ${ }^{[29]}$ Since size, composition and the method of electrode assembly were similar for both electrodes, we can assume the contact resistances are the same for both $\mathrm{MoO}_{3}$ and $\mathrm{MoO}_{3-\mathrm{x}}$, electrodes. Therefore, the difference in the $\mathrm{R}_{\text {semi }}$ could be directly related to the increased conductivity of the electrode material, which agrees with the result of electrical measurements of a single nanobelt (Figure 2d) and the FPC calculations (Figure 2c). Cyclic voltammetry (CV) of $\mathrm{MoO}_{3}$ and $\mathrm{MoO}_{3-\mathrm{x}}$ (hydrogenation temperature $350{ }^{\circ} \mathrm{C}$ ) at $50 \mathrm{mV} / \mathrm{s}$ was shown in Figure 3a. Compared to the $\mathrm{MoO}_{3} / \mathrm{CNT}$ electrodes, the $\mathrm{CV}$ of $\mathrm{MoO}_{3-\mathrm{x}} / \mathrm{CNT}$ electrodes showed much faster current responses at the switching potentials $(-0.1 \mathrm{~V}$ and $-0.9 \mathrm{~V})$ owing to their much lower charge transfer resistance. Besides, three couples of redox peaks appeared in CVs, which suggest enhanced reversible $\mathrm{Li}^{+}$intercalation in $\mathrm{MoO}_{3-\mathrm{x}}$ and provides a larger pseudocapacitance contribution, as demonstrated by a larger area under the CV curve.

The galvanostatic charge-discharge (GCD) curves of the $\mathrm{MoO}_{3-\mathrm{x}}$ (hydrogenation temperature $350{ }^{\circ} \mathrm{C}$ ) are shown in Figure $3 \mathrm{~b}$. Benefiting from the fast electron transport and $\mathrm{Li}^{+}$insertion/extraction, $\mathrm{MoO}_{3-\mathrm{x}} / \mathrm{CNT}$ electrodes show good Coulombic efficiency (>95\%) with low IR drops for all the tested current densities, as shown in Figure S6. The specific capacitance of the electrodes could be calculated from the GCD curves according to the following equations:

$$
\begin{aligned}
& C=I \Delta t / \Delta E \\
& C \mathrm{~s}=C / M=I \Delta t / M \Delta E
\end{aligned}
$$

where $C$ is the total capacitance $(\mathrm{F}), I$ is the discharge current $(\mathrm{mA}), \Delta t$ is the 
discharge time (s), $\Delta E$ is the potential window (V) after the IR drop, and $M$ is the mass loading of the $\mathrm{MoO}_{3}$. As shown in Figure 3c, the $\mathrm{MoO}_{3-\mathrm{x}}$ (hydrogenation temperature $350{ }^{\circ} \mathrm{C}$ ) showed the highest specific capacitance of $337 \mathrm{~F} / \mathrm{g}$ at $0.5 \mathrm{~A} / \mathrm{g}$ with excellent rate capability as indicated by a specific capacitance of $214 \mathrm{~F} / \mathrm{g}$ at 10 $\mathrm{A} / \mathrm{g}$ (retaining $63.6 \%$ of the $0.5 \mathrm{~A} / \mathrm{g}$ capacitance), which is much better than the previously studied negative electrodes and the rate capability was comparable with carbonaceous materials. ${ }^{[1,23,30]}$ Considering that the loading of the active material was as high as $2.5 \mathrm{mg} / \mathrm{cm}^{2}\left(0.86 \mathrm{~g} / \mathrm{cm}^{3}\right.$ density), these results reveal a potential of this material for SC electrode applications. The observed improved electrochemical performance is a result of: (1) Increased concentration of oxygen vacancies that have been successfully introduced in $\mathrm{MoO}_{3-\mathrm{x}}$ after hydrogenation, increasing the conductivity of $\mathrm{MoO}_{3-\mathrm{x}}$; (2) Improved conductivity results in faster electron transport even at very high mass loadings for freestanding $\mathrm{MoO}_{3-\mathrm{x}} / \mathrm{CNT}$ electrodes, facilitating the $\mathrm{Li}^{+}$transport; (3) Freestanding films provided hierarchical porous channels for effective electrolyte diffusion in the electrode and faster electron/ion channels, resulting in the high rate $\mathrm{Li}^{+}$intercalation and efficient utilization of pseudocapacitance of $\mathrm{MoO}_{3-\mathrm{x}}$. It is worth noting that when specific capacitance was calculated based on the total mass loading of $\mathrm{MoO}_{3-\mathrm{x}}$ and CNT, a value of $219 \mathrm{~F} / \mathrm{g}$ was obtained for the electrode mass loading of $3.8 \mathrm{mg} / \mathrm{cm}^{2}\left(1.33 \mathrm{~g} / \mathrm{cm}^{3}\right.$ density).

The study of the influence of the hydrogenation temperature on the performance of the electrodes has shown that when the temperature was below $200{ }^{\circ} \mathrm{C}$, there was no obvious change in capacitance compared to $\mathrm{MoO}_{3}$. However, the capacitance of electrodes increased at higher hydrogenation temperatures mainly due to the increased degree of reduction. However, the capacitance decreased when the hydrogenations temperature increased to $400{ }^{\circ} \mathrm{C}$, due to the excessive reduction. ${ }^{[31]}$ Since the capacitance of $\mathrm{MoO}_{2}$ is much lower than $\mathrm{MoO}_{3}$, a high content of $\mathrm{Mo}^{4+}$ may result in the decreased capacitance in samples hydrogenated at $400{ }^{\circ} \mathrm{C}\left(\mathrm{MoO}_{3-\mathrm{x}}-400{ }^{\circ} \mathrm{C}\right)$. It should be pointed out that the gravimetric capacitance might not be an appropriate metric to show the true performance of the material for practical applications. As 
suggested by Gogotsi and Simon, volumetric capacitance is a more appropriate metric to compare the performance of different electrode materials. ${ }^{[9]}$ Accordingly, the volumetric capacitance of the electrodes was calculated according to the following equations: ${ }^{[1,10,29]}$

$$
C_{\mathrm{v}}=C / V=I \Delta t / V \Delta E
$$

where $V$ is the volume of the electrode, which included the $\mathrm{MoO}_{3}$ and $\mathrm{CNT}\left(\mathrm{cm}^{3}\right)$. The highest achieved volumetric capacitance of the whole electrode was $\sim 291 \mathrm{~F} / \mathrm{cm}^{3}$ which is comparable to recently reported materials with high volumetric capacitance such as layered $\mathrm{Ti}_{3} \mathrm{C}_{2} \mathrm{~T}_{\mathrm{x}}\left(\sim 330 \mathrm{~F} / \mathrm{cm}^{3}\right)$ and graphene film $\left(376 \mathrm{~F} / \mathrm{cm}^{3}\right)$ and much larger than porous carbonaceous materials (less than $180 \mathrm{~F} / \mathrm{cm}^{3}$ ). ${ }^{[32-33]}$ Since $\mathrm{MoO}_{3-\mathrm{x}}$ was dispersed well in the whole electrode, freestanding film allows to improve the volume utilization with good mechanical stability, conductivity and flexibility of electrodes. ${ }^{[28,34]}$

To further understand the kinetics of $\mathrm{Li}^{+}$intercalation in $\mathrm{MoO}_{3-\mathrm{x}}$, $\mathrm{CVs}$ at different scan rates were recorded and presented in Figures 3a, 4a and S7. As a typical example, three couples of peaks can be detected in Figure $4 \mathrm{a}$. They were denoted as $A_{1} / A_{2}$, $\mathrm{B}_{1} / \mathrm{B}_{2}$ and $\mathrm{C}_{1} / \mathrm{C}_{2}$, and attributed to the multistep $\mathrm{Li}^{+}$intercalation in interlayer and intralayer space of $\mathrm{MoO}_{3-\mathrm{x}} \cdot{ }^{[35]}$ The peak potential shifts of these couples at different sweep rates were recorded with the peaks position at $2 \mathrm{mV} / \mathrm{s}$ scan rate as the baseline. The largest peak potential shift was $0.09 \mathrm{~V}$ for $\mathrm{A}_{1}$ at $50 \mathrm{mV} / \mathrm{s}$ in Figure $4 \mathrm{~b}$. The shifts for other peaks were much lower than this value as shown in Figures 4b-c, suggesting the structure of $\mathrm{MoO}_{3-\mathrm{x}}$ facilitates the surface-controlled $\mathrm{Li}^{+}$intercalation, similar to the intercalation behavior observed for layered oxides such as $\mathrm{Nb}_{2} \mathrm{O}_{5}$ having two-dimensional $\mathrm{Li}^{+}$intercalations channels. ${ }^{[19]}$ For many $\mathrm{Li}^{+}$intercalating materials reported in the literature, the peak potential shifts were significant even at scan rates as low as $0.1 \mathrm{mV} / \mathrm{s}$, indicating the insertion/extraction process was diffusion-controlled associated with phase changes.

Besides, the relationship between peak current and sweep rates was also analyzed based on the following equation: 


$$
i=a v^{b}
$$

where $i$ is the peak current $(\mathrm{mA}), v$ is the sweep rate $(\mathrm{mV} / \mathrm{s}), a$ and $b$ are coefficients. The process could be deemed as diffusion-controlled if $b=0.5$ and surface-controlled if $b=1$. The plots of the peak current as a function of sweep rate are shown in Figure $4 \mathrm{~d}-\mathrm{f}$. The slope identifies the $b$ value of each peak. Although $b$ values for $\mathrm{B}_{1} / \mathrm{B}_{2}$ and $C_{1} / C_{2}$ couples were slightly lower than that of the $A_{1} / A_{2}$ couple, they were still $\geq 0.8$, indicating the intercalation process in $\mathrm{MoO}_{3-\mathrm{x}}$ was more likely surface-controlled, which agrees well with the observed small peak potential shifts at different scan rates. ${ }^{[19-20]}$ Based on the results and discussion above, it could be concluded that the kinetic process in $\mathrm{MoO}_{3-\mathrm{x}}$ is related to surface charge storage and results in the observed high rate behavior. $\mathrm{MoO}_{3}$ consists of layered $\mathrm{MoO}_{6}$ octahedra with interlayer gaps that form the natural tunnels for $\mathrm{Li}^{+}$insertion and extraction. For both $\mathrm{MoO}_{3}$ and $\mathrm{MoO}_{3-\mathrm{x}}$, the intercalation process should be the same since they are similar in structure and shape, and most importantly have similar $b$ values (see Figure S8). However, the lower electronic conductivity in $\mathrm{MoO}_{3}$ hinders the process of transfer of electrons to $\mathrm{Li}^{+}$ions, resulting in lower electrochemical performance even at low sweep rates. After hydrogenation, the $2 \mathrm{D} \mathrm{Li}^{+}$insertion/extraction channels of $\mathrm{MoO}_{3}$ are still available, but with an enhanced electron conductivity more electrons can react with the inserted $\mathrm{Li}^{+}$ions, thus increasing the intercalation pseudocapacitance. Even at high rates, the fast electron mobility in $\mathrm{MoO}_{3-\mathrm{x}}$ guarantees the effective translation from the inserted $\mathrm{Li}^{+}$into intercalation pseudocapacitance leading to excellent rate capability. $\mathrm{MoO}_{3-\mathrm{x}}$ is a promising candidate for the negative electrode of $\mathrm{Li}$-ion capacitors, providing high volumetric capacitance, excellent rate capability, high energy and power density, even for electrodes with large mass loadings.

\section{Conclusions}

In conclusion, we have demonstrated the hydrogenation is an efficient way to increase the conductivity of $\mathrm{MoO}_{3}$ and improve its electrochemical performance as a result. Also, first principle calculation implied enhanced conductivity of $\mathrm{MoO}_{3-\mathrm{x}}$ based on DOS after hydrogenation. Freestanding $\mathrm{MoO}_{3-\mathrm{x}} / \mathrm{CNT}$ films show a much faster 
current response in an aqueous electrolyte compared with $\mathrm{MoO}_{3} / \mathrm{CNT}$ films, a specific capacitance of $337 \mathrm{~F} / \mathrm{g}$ (based on the mass of $\mathrm{MoO}_{3-\mathrm{x}}$ ) and a high volumetric capacitance of $291 \mathrm{~F} / \mathrm{cm}^{3}$ (based on the volume of the whole electrode) with excellent rate capability. Since the intercalation kinetics for both the $\mathrm{MoO}_{3}$ and $\mathrm{MoO}_{3-\mathrm{x}}$ were surface-controlled, the increased intercalation pseudocapacitance is attributed to the higher electron conductivity of $\mathrm{MoO}_{3-\mathrm{x}}$, which facilitates the reaction between electrons and $\mathrm{Li}^{+}$ions and resulted in better utilization of $\mathrm{Li}^{+}$intercalation. This capacitive behavior implied that $\mathrm{MoO}_{3-\mathrm{x}}$ could be used as a negative electrode with both high energy and power density under high mass loading. A similar partial reduction approach may be applicable to other transition metal oxides.

\section{Acknowledgements}

This work was financially supported by the National Natural Science Foundation of China (51322210, 51002056), a Foundation for the Author of National Excellent Doctoral Dissertation of PR China (201035), and the Fundamental Research Funds for the Central Universities (HUST: 2012YQ025, 2013YQ049, 2013TS160). X. Xiao thanks the independent innovation funding of WNLO (0118187081). The authors thank Mr. Bin Yao, Mr. T. Q. Li, Mr. Y. Z. Cao, Mr. G. Li, Dr. Q. P. Luo, and Prof. J. Chen for their help. The authors also thank to the facility support of the Center for Nanoscale Characterization \& Devices (CNCD), WNLO-HUST and the Analysis and Testing Center of Huazhong University of Science and Technology.

\section{References}

[1] D. Pech, M. Brunet, H. Durou, P. Huang, V. Mochalin, Y. Gogotsi, P. L. Taberna, P. Simon, Nature Nanotechnology 5 (2010) 651.

[2] Q. Zhong, J. Zhong, B. Hu, Q. Hu, J. Zhou, Z. Wang, Energy Environmental Science 6 (2013) 1779.

[3] P. Simon, Y. Gogotsi, Nature Materials 7 (2008) 845.

[4] T. Chen, L. Qiu, Z. Yang, Z. Cai, J. Ren, H. Li, H. Lin, X. Sun, H. Peng, Angewandte Chemie International Edition 51 (2012) 11977. 
[5] X. Xiao, L. Yuan, J. Zhong, T. Ding, Y. Liu, Z. Cai, Y. Rong, H. Han, J. Zhou, Z. L. Wang, Advanced Materials 23 (2011) 5440.

[6] L. Yuan, X. Xiao, T. Ding, J. Zhong, X. Zhang, Y. Shen, B. Hu, Y. Huang, J. Zhou, Z. L. Wang, Angewandte Chemie International Edition 51 (2012) 4934.

[7] L. Hu, J. W. Choi, Y. Yang, S. Jeong, F. La Mantia, L. F. Cui, Y. Cui, Proceedings of the National Academy of Sciences U.S.A. 106 (2009) 21490.

[8] Y. Zhu, S. Murali, M. D. Stoller, K. J. Ganesh, W. Cai, P. J. Ferreira, A. Pirkle, R. M. Wallace, K. A. Cychosz, M. Thommes, D. Su, E. A. Stach, R. S. Ruoff, Science 332 (2011) 1537.

[9] Y. Gogotsi, P. Simon, Science 334 (2011) 917.

[10] M. D. Stoller, R. S. Ruoff, Energy Environmental Science 3 (2010) 1294.

[11] (a) P. Yang, X. Xiao, Y. Li, Y. Ding, P. Qiang, X. Tan, W. Mai, Z. Lin, W. Wu, T. Li, H. Jin, P. Liu, J. Zhou, C. P. Wong, Z. L. Wang, ACS Nano 7 (2013) 2617. (b) J. Liu, J. Jiang, C. Cheng, H. Li, J. Zhang, H. Gong, H. J. Fan, Advanced Materials 23 (2011) 2076.

[12] X. Xiao, T. Li, P. Yang, Y. Gao, H. Jin, W. Ni, W. Zhan, X. Zhang, Y. Cao, J. Zhong, L. Gong, W. C. Yen, W. Mai, J. Chen, K. Huo, Y. L. Chueh, Z. L. Wang, J. Zhou, ACS Nano 6 (2012) 9200.

[13] J. Zhang, J. Jiang, H. Li, X. S. Zhao, Energy Environmental Science 4 (2011) 4009.

[14] X. Lu, M. Yu, G. Wang, T. Zhai, S. Xie, Y. Ling, Y. Tong, Y. Li, Advanced Materials 25 (2013) 267.

[15] Z. Fan, J. Yan, T. Wei, L. Zhi, G. Ning, T. Li, F. Wei, Advanced Functional Materials 21 (2011) 2366.

[16] T. Zhai, F. Wang, M. H. Yu, S. Xie, C. Liang, C. Li, F. Xiao, R. Tang, Q. Wu, X. H. Lu, Y. Tong, Nanoscale 5 (2013) 6790.

[17] J. Y. Luo, Y. Y. Xia, Journal of Power Sources 186 (2009) 224.

[18] (a) N. Nagarajan, I. Zhitomirsky, Journal of Applied Electrochemisty 36 (2006) 1399.(b) Q. Qu, S. Yang, X. Feng, Advanced Materials 23 (2011) 5574.

[19] P. Simon, Y. Gogotsi, B. Dunn, Science 343 (2014) 1210. 
[20] (a) V. Augustyn, J. Come, M. A. Lowe, J. W. Kim, P.-L. Taberna, S. H. Tolbert, H. D. Abruña, P. Simon, B. Dunn, Nature Materials 12 (2013) 518. (b) J. Wang, J. Polleux, J. Lim, B. Dunn, Journal of Physical Chemistry C 111 (2007) 14925.

[21] T. Brezesinski, J. Wang, S. H. Tolbert, B. Dunn, Nature Materials 9 (2010) 146.

[22] L. Q. Mai, B. Hu, W. Chen, Y. Y. Qi, C. S. Lao, R. S. Yang, Y. Dai, Z. L. Wang, Advanced Materials 19 (2007) 3712.

[23] X. Xiao, T. Ding, L. Yuan, Y. Shen, Q. Zhong, X. Zhang, Y. Cao, B. Hu, T. Zhai, L. Gong, J. Chen, Y. Tong, J. Zhou, Z. L. Wang, Advanced Energy Materials 2 (2012) 1328.

[24] G. R. Li, Z. L. Wang, F. L. Zheng, Y. N. Ou, Y. X. Tong, Journal of Materials Chemistry 21 (2011) 4217.

[25] (a) J. M. Soler, E. Artacho, J. D. Gale, A. García, J. Junquera, P. Ordejón and D. Sánchez-Portal, Journal of Physics: Condensed Matter 14 (2002) 2745. (b) G. Román-Pérez and J. M. Soler, Physical Review Letters 103 (2009) 096102. (c) P. Hohenberg, W. Kohn, Physical Review 136 (1964) B864. (d) W. Kohn, L. J. Sham, Physical Review 140 (1965) A1133. (e) J. P. Perdew, K. Burke, M. Ernzerhof, Physical Review Letters 77 (1996) 3865. (f) T. Ressler, R. E. Jentoft, J. Wienold, M. M. Günter, O. Timpe, Journal of Physical Chemistry B 104 (2000) 6360. (g) M. E. Kurtoglu, T. Longenbach, Y. Gogotsi, Journal of Materials Chemistry 21 (2011) 7931.

[26] L. Cai, P. M. Rao, X. Zheng, Nano Letters 11 (2011) 872.

[27] G. Wang, J. Ni, H. Wang, L. Gao, Journal of Materials Chemistry A 1 (2013) 4112.

[28] X. Xiao, X. Peng, H. Jin, T. Li, C. Zhang, B. Gao, B. Hu, K. Huo, J. Zhou, Advanced Materials 25 (2013) 5091.

[29] P. Simon, Y. Gogotsi, Accouts of Chemical Research 46 (2013) 1094.

[30] E. Frackowiak, F. Béguin, Carbon 39 (2001) 937.

[31] X. Lu, G. Wang, T. Zhai, M. Yu, J. Gan, Y. Tong, Y. Li, Nano Letters 12 (2012) 
1690.

[32] J. Chmiola, C. Largeot, P.-L. Taberna, P. Simon, Y. Gogotsi, Science 328 (2010) 480 .

[33] (a) M. R. Lukatskaya, O. Mashtalir, C. E. Ren, Y. Dall'Agnese, P. Rozier, P. L. Taberna, M. Naguib, P. Simon, M. W. Barsoum, Y. Gogotsi, Science 341 (2013) 1502. (b) Y. Tao, X. Xie, W. Lv, D.-M. Tang, D. Kong, Z. Huang, H. Nishihara, T. Ishii, B. Li, D. Golberg, F. Kang, T. Kyotani, Q.-H. Yang, Scientific Reports 3 (2013) 2975.

[34] S. D. Perera, B. Patel, N. Nijem, K. Roodenko, O. Seitz, J. P. Ferraris, Y. J. Chabal, K. J. Balkus, Advanced Energy Materials 1 (2011) 936.

[35] W. Li, F. Cheng, Z. Tao, J. Chen, Journal of Physical Chemistry B 110 (2005) 119.

\section{Figures}



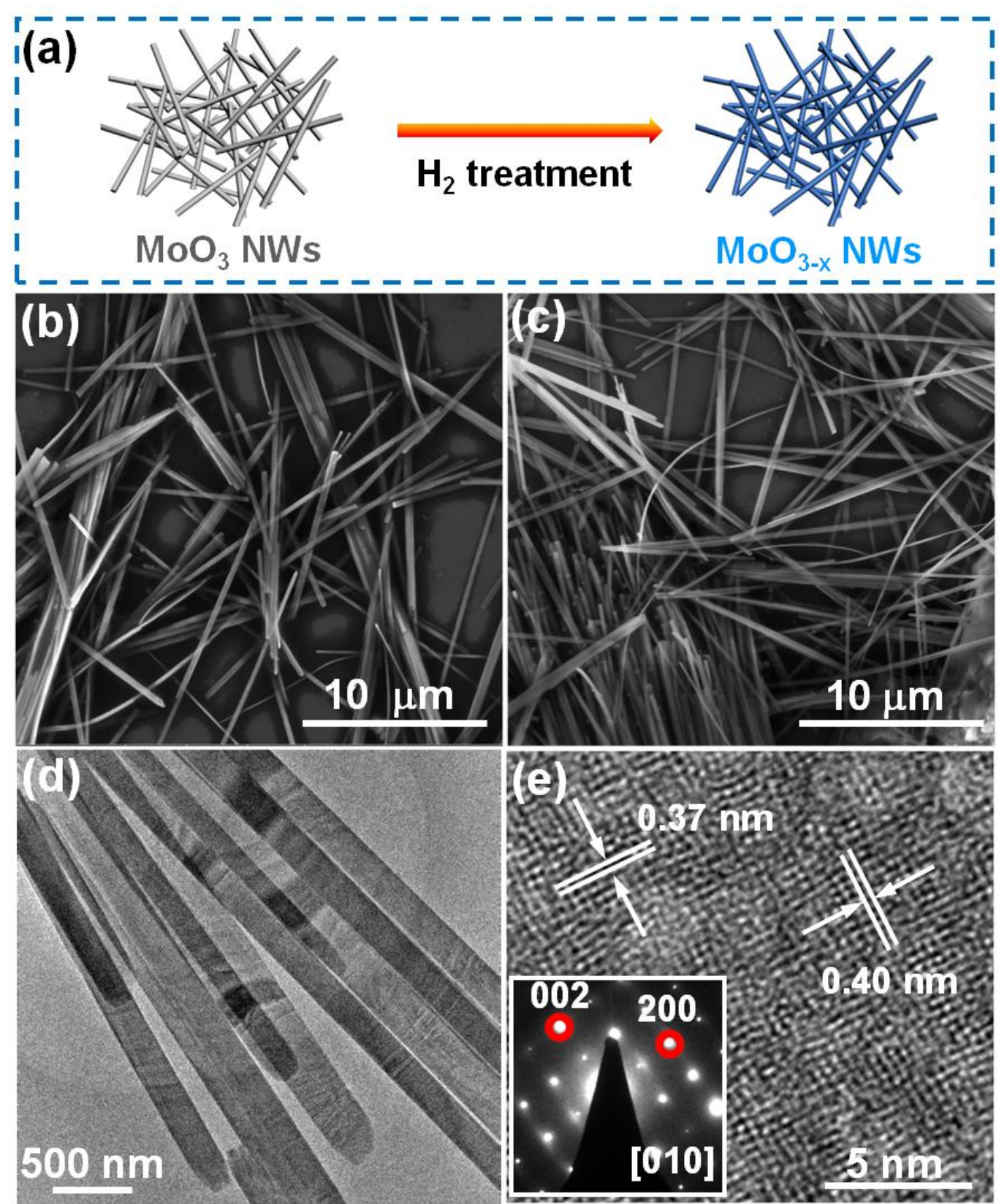

Figure 1. (a) Schematic of hydrogenation procedure for $\mathrm{MoO}_{3-\mathrm{x}}$. (b) and (c) SEM images of $\mathrm{MoO}_{3}$ and $\mathrm{MoO}_{3-\mathrm{x}}$ nanobelts. (d) Low resolution TEM image of $\mathrm{MoO}_{3-\mathrm{x}}$. (e) High resolution TEM images of $\mathrm{MoO}_{3-\mathrm{x}}$. The inset in (e) is SAED pattern. 

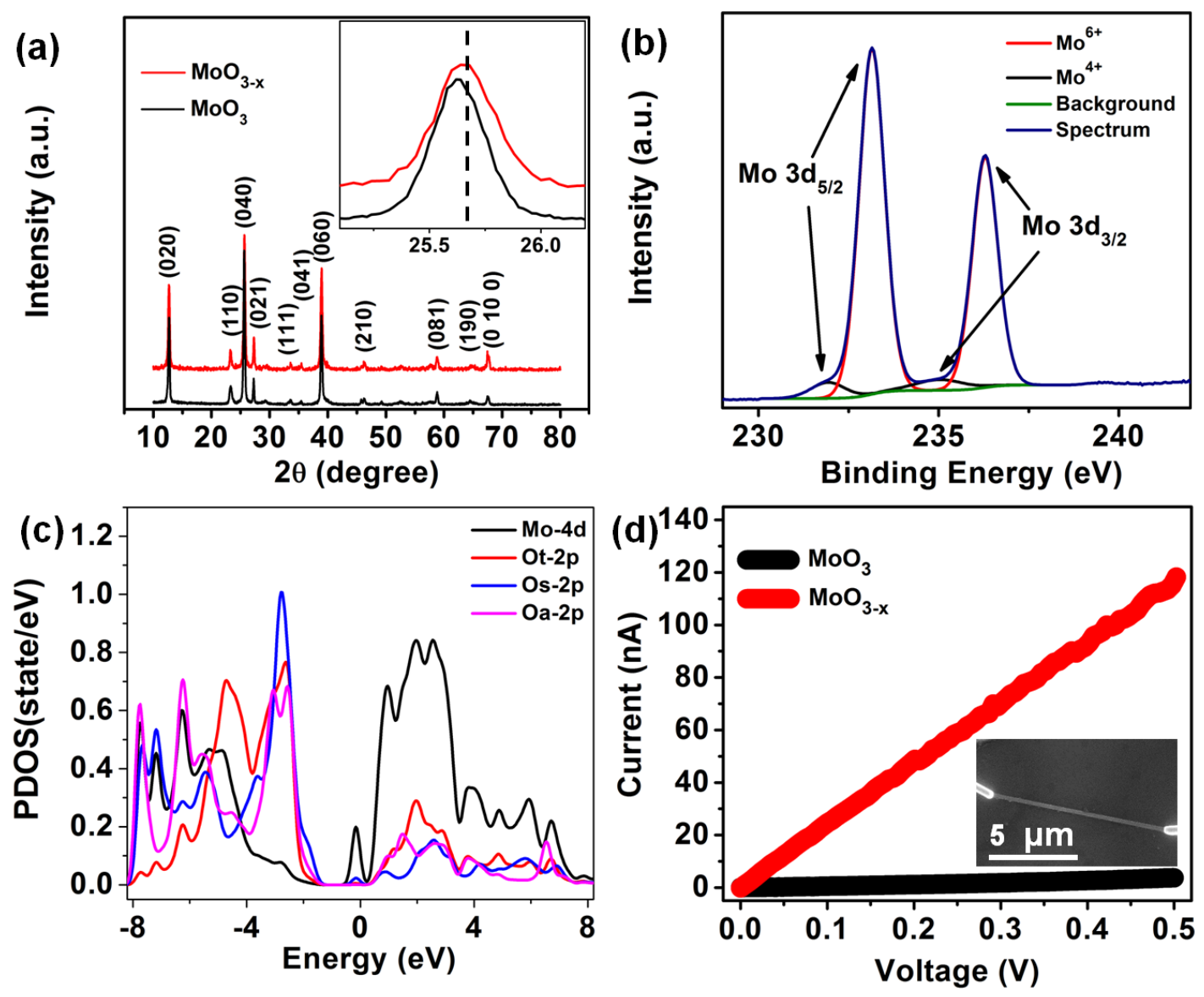

Figure 2. (a) XRD patterns of $\mathrm{MoO}_{3}$ and $\mathrm{MoO}_{3-\mathrm{x}}$. The inset shows the detectable shift for different samples which was due to the hydrogenation. (b) XPS spectrum of $\mathrm{MoO}_{3-\mathrm{x}}$. (c) The partial density of states of $\mathrm{MoO}_{3-\mathrm{x}}$ with Oa defect from first principle calculations. (d) $I-V$ curves of $\mathrm{MoO}_{3}$ and $\mathrm{MoO}_{3-\mathrm{x}}$. 

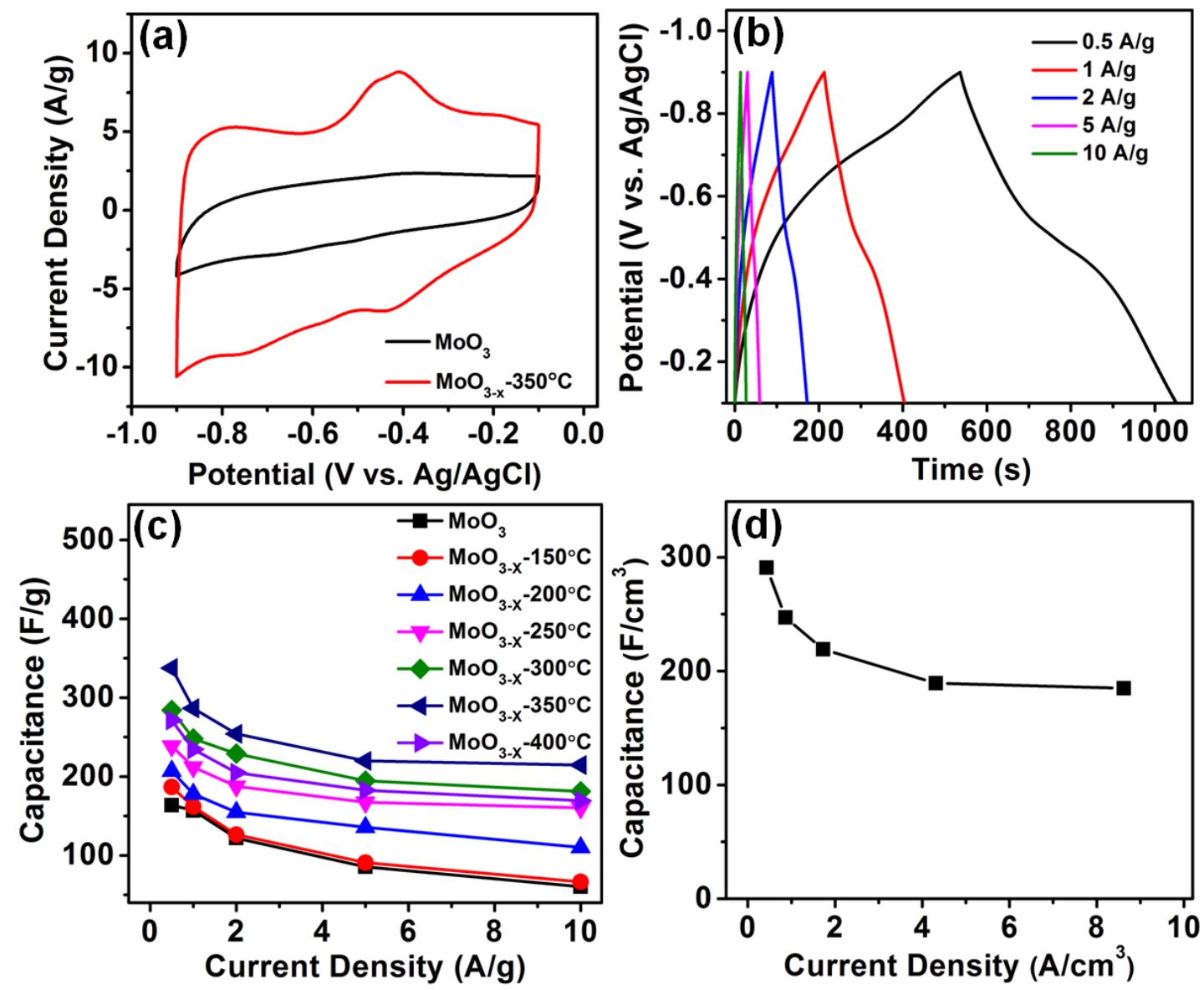

Figure 3. (a) $\mathrm{CV}$ curves of freestanding $\mathrm{MoO}_{3}, \mathrm{MoO}_{3-\mathrm{x}}$ (hydrogenated at $350{ }^{\circ} \mathrm{C}$ ) electrode (mixing with $35 \mathrm{wt} \% \mathrm{CNT}$ ) under the same mass loading by a typical three-electrode configuration at $50 \mathrm{mV} / \mathrm{s}$. The electrolyte is $5 \mathrm{M} \mathrm{LiCl}$, counter electrode is YP-50 and the reference electrode is $\mathrm{Ag} / \mathrm{AgCl}$. (b) Galvanostatic charge/discharge curves of freestanding $\mathrm{MoO}_{3-\mathrm{x}} / \mathrm{CNT}$ electrode. (c) Gravimetric capacitance as a function of current density for samples hydrogenated at different temperatures. The samples are denoted as " $\mathrm{MoO}_{3-\mathrm{x}}$-hydrogenated temperature". (d) volumetric capacitance as a function of current density for $\mathrm{MoO}_{3-\mathrm{x}}-350{ }^{\circ} \mathrm{C}$. This value is based on the whole electrode which includes the $\mathrm{MoO}_{3-\mathrm{x}}$ and CNT. 

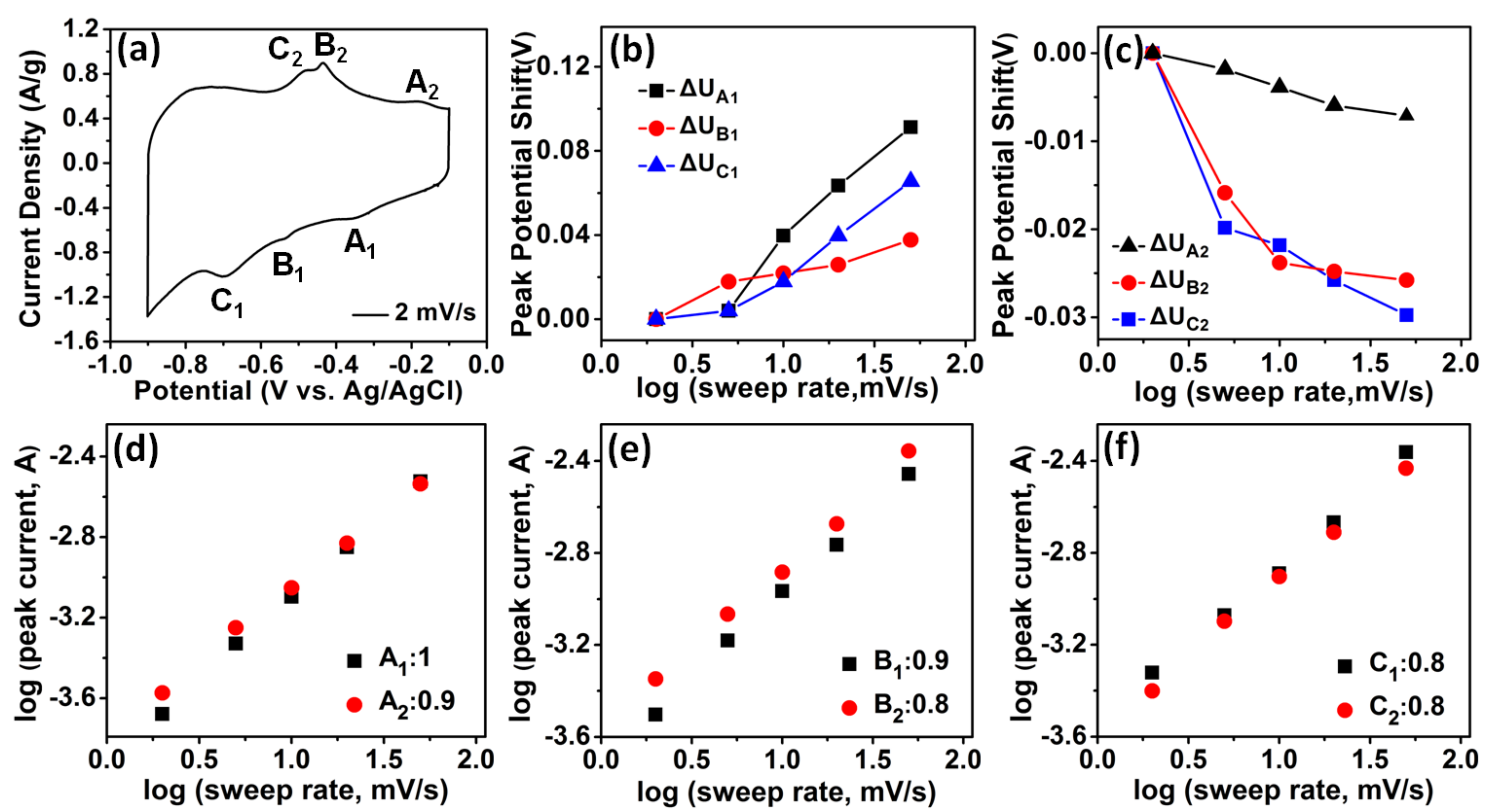

Figure 4. Analysis of electrochemical behavior and charge-discharge kinetics. (a) CV curve for freestanding $\mathrm{MoO}_{3-\mathrm{x}} / \mathrm{CNT}$ electrode at $2 \mathrm{mV} / \mathrm{s}$ sweep rate. (b) and (c) peak potential shift as a function of sweep rates for each peak. (d) (f) b values of each peak. 
Freestanding $\mathrm{MoO}_{3-\mathrm{x}}$ nanobelt/carbon nanotube films for $\mathrm{Li}$-ion intercalation pseudocapacitors

Xu Xiao, ${ }^{\mathrm{a}, \mathrm{b}}$ Zehua Peng, ${ }^{\mathrm{a}}$ Chi Chen, ${ }^{\mathrm{a}}$ Chuanfang Zhang, ${ }^{\mathrm{b}}$ Majid Beidaghi, ${ }^{\mathrm{b}}$ Zhenhua Yang, ${ }^{\mathrm{a}}$ Nan Wu, ${ }^{\mathrm{a}}$ Yunhui Huang, ${ }^{\mathrm{c}}$ Ling Miao, ${ }^{\mathrm{a}}$ Yury Gogotsi, ${ }^{\mathrm{b}}$ and Jun Zhou ${ }^{\mathrm{a} *}$

\section{Graphical abstract}

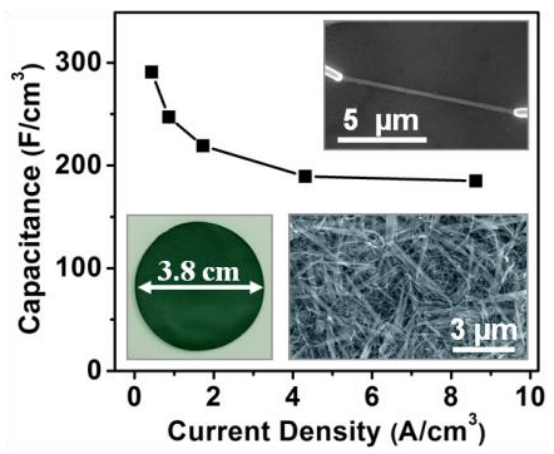

